\title{
A Notação Gregoriana: Gênese e Significado
}

\author{
LoREnZo MAMMI
}

\section{Notação e Forma Musical}

A tarefa de transcrever notações antigas costuma ser ingrata: no esforço de destrinçar as complexas partituras góticas, ou de interpretar a escrita aparentemente sumária da monodia gregoriana, sempre permanece a sensação de que algo de essencial se perca, e que a música transcrita não seja, na substância, a mesma música.

Com efeito, a notação musical não é mero instrumento de registro e transmissão de um conteúdo já plenamente articulado no campo da audição: ela traduz o evento sonoro em símbolos visuais, mas também o interpreta segundo um certo modelo, uma certa hierarquia de valores. Como bem sabem os etnomusicólogos, toda transcrição comporta a seleção de elementos sonoros considerados significativos, e a exclusão de outros considerados irrelevantes, seleção que, em grande parte, não é anterior à escrita. A partir de um único evento sonoro é possível escrever partituras diferentes, e cada uma representa uma forma musical diferente, não apenas uma transcrição diferente da mesma forma. A notação, portanto, é um elemento formante das obras, influi sobre ela e é por ela influenciada.

Sem dúvida, a escrita, tanto musical quanto verbal, funciona sempre como uma espécie de filtro: os aspectos do evento sonoro que ela inclui passam a ser considerados significativos, os que exclui, tornam-se contingentes e irrelevantes. Mas a língua falada trabalha com unidades sonoras já cristalizadas num código, e para transcrevê-las no papel é suficiente en- 
contrar um código visual correspondente. Esse código dará conta não tanto do som da fala, quanto dos aspectos que a língua já selecionou nele como elementos significativos. No caso da música, ao contrário, todos os aspectos do som podem virtualmente ser considerados significativos, e a seleção se realiza diretamente no plano da escrita; além disso, os elementos de base de uma peça musical não possuem um significado em si, dependendo totalmente do contexto; por isso, cada inclusão ou exclusão comporta uma redefinição do sistema simbólico como um todo.

Toda transcrição ou tradução pressupõe obviamente um conteúdo comum entre a versão original e a transposta. A gravura que reproduz um quadro tenta se manter fiel ao desenho e ao claro-escuro, enquanto as relações de cor são substituídas por relações entre tipos diferentes de retículos. Um texto traduzido respeita o significado denotativo do original e, na medida do possível, suas conotações, sua organização sintática e sonora. Mas o que exatamente una partitura antiga tem em comum com sua transcrição moderna? A resposta mais óbvia é: permanece o evento sonoro a ser realizado, enquanto mudam os caminhos pelos quais o intérprete chega a essa realização. Se, por exemplo, acrescentamos a uma partitura de Palestrina as linhas de compasso, ausentes no original, as durações das notas não mudam, mas o intérprete moderno poderá medila com um sistema a ele mais familiar.

No entanto, a linha de compasso não é apenas um instrumento neutro de medida: ela estrutura o texto musical em células métricas fixas, células que eram absolutamente estranhas ao pensamento musical renascentista. Palestrina concebia as frases musicais como linhas contínuas e indivisíveis, e não como conjuntos de células. O intérprete moderno, portanto, se não quiser violentar o texto, deverá esquecer os compassos para tentar reconstruir a fluência da curva melódica - num certo sentido, deverá trabalhar contra a transcrição, extraindo dela, mentalmente, a escrita original.

Esse esforço de reconstrução, porém, pode não ser suficiente, sobretudo no que diz respeito às notações mais antigas. O que muda, nesse caso, não é apenas a maneira de organizar o material, mas também as unidades mínimas de que esse material é constituído: a notação gregoriana, por exemplo, não se baseia na nota isolada, mas em signos (neumas) que representam um certo tipo de movimento melódico, sem indicar alturas ou durações determinadas. $\mathrm{O}$ transcritor moderno é obrigado a segmentar 
esses signos em seqüências de notas de altura definida, sinalizando eventualmente, com ligaduras, a distribuição original das notas nos neumas. Mas os neumas não eram conjuntos de notas: eram descrições de movimentos, indicando onde a voz deveria tomar impulso, onde encontraria repouso, etc. Essas informações são impossíveis de ser reproduzidas na transcrição.

$\mathrm{Na}$ tradição ocidental, cada geração, e quase cada autor e cada obra, redefinem os limites e a estruturas da notação. Isso é evidente até em tempos recentes, quando a notação passa a se basear num código relativamente estável: quando Rossini resolveu escrever por extenso as cadências de suas árias, ou quando Chopin encontrou uma grafia para seus rubato, elementos já presentes na prática, com função decorativa ou expressiva, tornaram-se significativos no plano da composição. $\mathrm{O}$ affetto musical deixou de ser claramente distinto da estrutura, e passou a influir sobre ela, determinando-a e sendo por ela determinado. Os trechos "em notas pequenas", um tempo meramente decorativos, passam a ser fundamentais para a definição formal da obra, gerando uma oscilação estrutural, e não meramente contingente, entre o tempo regular do compasso e o tempo livre das cadências e dos rubato. Um transcritor do futuro, que quisesse reduzir todas as notas a durações exatamente definidas, perderia evidentemente o sentido profundo dessa oscilação, tipicamente romântica. Reproduziria, então, o aspecto exterior do evento sonoro, mas não seu significado.

A interação contínua entre composição, notação e interpretação parece ser uma característica própria da música ocidental, a partir da era cristã. Tanto as notação musical antiga quanto a maior parte das notações extra-européias utilizam notações alfabéticas, em analogia com a escrita. Os manuscritos musicais gregorianos a partir do século VIII, e os bizantinos, que remontam mais ou menos ao mesmo período, são os primeiros exemplos de notações baseadas sobre critérios totalmente diferentes, que não encontram paralelos imediatos fora da esfera musical. É necessário então analisar a natureza desses critérios, e sua funcionalidade em relação aos princípios musicais correntes na época.

\section{2. Índices e Ícones}

Em seu ensaio sobre a origem da notação ocidental (1982), Leo Treitler aproveita uma distinção semiótica para classificar tipos diferen- 
tes de notação. Segundo essa distinção, introduzida por Charles Pierce, um signo se relaciona com seu objeto como símbolo, ícone ou índice.

O símbolo não mantém nenhum tipo de relação formal com a coisa significada. Baseia-se sobre uma convenção, que pode não ser totalmente arbitrária, mas em todo caso não é estabelecida a partir de semelhanças formais. O símbolo é particularmente adequado, portanto, quando a coisa significada é abstrata, ou, mesmo sendo concreta, não é visível. Exemplos típicos são as letras do alfabeto, que representam simbolicamente fonemas.

O ícone, ao contrário, possui uma analogia formal com seu objeto. A cruz é um símbolo quando representa o Cristianismo, mas se torna um ícone quando posta numa estrada para sinalizar um cruzamento.

$\mathrm{O}$ índice é algo mais complexo. Ele se relaciona com seu objeto por uma certa cadeia seqüencial. Essa relação pode ser a de um efeito com sua causa (índice descritivo; por exemplo: a fumaça é índice do fogo, ou o rastro de um animal é índice de sua passagem); ou pode ser a de uma ordem com sua execução (índice imperativo): as cores de um farol são índices imperativos, porque eles determinam uma ação.

A escrita musical moderna admite os três tipos de signos. As harmonizações de música popular, nas quais os acordes são representados por letras e/ou números, são simbólicas. Por outro lado, as grades que reproduzem esquematicamente o braço do violão ou do alaúde, nos manuais modernos como nas antigas tablaturas, carregam marcas que sugerem a posição dos dedos para cada som a ser obtido, e são portanto índices imperativos.

A notação em pauta, por outro lado, possui um estatuto ambíguo. Ainda que se destine à execução, ela não é indiciária, porque a maioria de seus signos se refere diretamente a sons, e apenas indiretamente aos gestos necessários para produzi-los. É simbólica, em parte, porque nela a relação entre signo e significado é arbitrária por muitos aspectos. A duração proporcional dos sons, por exemplo, é indicada pela forma das notas, que são totalmente convencionais. Os signos dinâmicos também são símbolos, na medida em que utilizam letras ou outras cifras para significar variações de volume ou de ataque ${ }^{1}$. O parâmetro das alturas,

1. As linhas divergentes ou convergentes que indicam acréscimo ou decréscimo progressivo da dinâmica poderiam ser consideradas icônicas, porque, uma vez aceita a 
ao contrário, não é representado por um vocabulário de signos específicos, mas pela posição dos signos (notas) no espaço. A altura é indicada pela posição da nota, não por sua forma, e uma seqüência de notas ao longo da pauta forma um desenho que consideramos intuitivamente como a reprodução de uma linha musical. Entre as notas tomadas singularmente e a linha que elas formam no conjunto há portanto uma diferença substancial: aquelas são símbolos dos sons, essa é um ícone da forma melódica. Os contornos que a escrita traça, no entanto, não existem senão a partir dela, porque os sons, em si, não produzem linhas. A rigor, a passagem de um som a outro não é um movimento, mas uma transformação. A notação, portanto, não se limita a reproduzir movimentos no espaço sonoro: ela cria a intuição desse espaço e desses movimentos ${ }^{2}$.

O caráter icônico da escrita musical moderna se baseia em duas analogias preliminares: o correr do tempo é representado no papel por um movimento de esquerda para direita; a oposição grave/agudo é realizada graficamente pela oposição baixo/alto. Essas correspondências são arbitrárias, e portanto simbólicas. Todavia, não são signos, mas apenas convenções que permitem a criação de um campo de representação. A primeira delas é bastante óbvia, porque deriva do movimento da escrita. A segunda é mais problemática e mais recente. Com efeito, a música grega adotou por muito tempo a relação inverti$\mathrm{da}$, como testemunham os nomes das notas: hypate hypatón (a mais alta das altas) era o nome grego do SI, nota mais grave do tetracordo mais grave do sistema (abaixo dela havia ainda o LÁ, chamado proslambanomenos, nota acrescentada, porque não pertencia a nenhum tetracordo); o lá, nota mais aguda, era chamada nete huperboláion

analogia fundamental (variação do espaço entre as linhas=variação de volume), há nelas um certo isomorfismo com a coisa representada. Tal isomorfismo, no entanto, permanece apenas esboçado, e se cristaliza rapidamente em símbolo.

2. K. Lévy, "Byzantine rite, music of the", New Grove III, utiliza os termos digital/ analógico no lugar de simbólico/icônico, alternativa que o próprio Treitler admite como possível. Ainda no New Grove (XIII, verbete "Notation"), Ian Bent propõe a oposição fônico/gráfico com o mesmo sentido. Em geral, a distinção da notação em dois grupos parece ser aceita pela maioria dos autores, embora haja uma grande variação nas definições e na terminologia. Talvez os termos utilizados por Levy e Bent sejam mais precisos tecnicamente daqueles de Treitler/Peirce, mas preferi manter a oposição simbólico/icônico devido à relação mais transparente que ela permite estabelecer com outros sistemas de escrita e outras formas de expressão ou de organização cultural. 
(a mais baixa das notas acrescentadas). Segundo a maioria dos pesquisadores, essas denominações derivavam da prática da lira, que era segurada em posição oblíqua, com as cordas mais graves para o alto. Sachs observou, porém, que a mesma analogia se encontra em outras culturas, e talvez se deva à simples observação de que instrumentos maiores (mais altos) produzem sons mais graves ${ }^{3}$.

De qualquer maneira, a relação entre a freqüência de uma nota e uma certa posição no espaço era, para os gregos, apenas contingente. Numa época indeterminada (provavelmente nos tempos de Aristoxenos), a analogia foi invertida e foi adotada a disposição ainda hoje em uso, sem que a inovação merecesse algum tipo de comentário por parte dos teóricos ${ }^{4}$.

A questão, de fato, era irrelevante naquele contexto, porque os gregos nunca tentaram desenvolver um modelo espacial do movimento musical. Para eles, as alturas eram atributos específicos de cada som, mais do que funções de uma linha melódica. Formas espaciais, predominantemente geométricas, podiam ser aproveitadas para esclarecer o cálculo dos intervalos nos tratados científicos ${ }^{5}$, nunca porém para pôr no papel uma composição específica. Para essa última tarefa era suficiente marcar por um símbolo, normalmente uma letra do alfabeto mais ou menos modificada, a altura da nota a ser cantada ou executada. Se não fosse possível deduzir diretamente a duração pelas sílabas do texto, podia ser acrescentado um sinal específico: nada para a sílaba breve (um tempo), um traço horizontal para a longa (dois tempos), um traço e um ponto para uma longa prolongada (três tempos) e assim em diante. Nem todas as notas, aliás, eram escritas: algumas permaneciam subentendidas porque, analogamente às durações, a acentuação do texto as tornava óbvias. O início da segunda estrofe do primeiro hino délfico (138 a. C.) apresenta $o$ seguinte aspecto no original grego ${ }^{6}$ :

3. Sachs, 1943, 61 e 226; cf. Reese, 1940, 32.

4. Os nomes dos tropoi, escalas de transposição que constituem o fruto tardio do sistema musical grego, já identificam o mais grave com o mais baixo: por exemplo, a mesé do tropos hipofrígio (abaixo do frígio) é de uma quarta mais grave, a do hiperfrígio (acima do frígio) de uma quarta mais aguda em relação à mesé do frígio.

5. Tais figuras eram, aliás, apenas reproduções estilizadas de instrumentos, normalmente do monocórdio, com linhas recurvas que marcavam os lugares a serem pressionados para obter os intervalos desejados.

6. A transcrição completa do hino, com a notação original superposta à moderna, encontra-se em Doutzaris, 1934, pp. 338-340. 
Figura 1

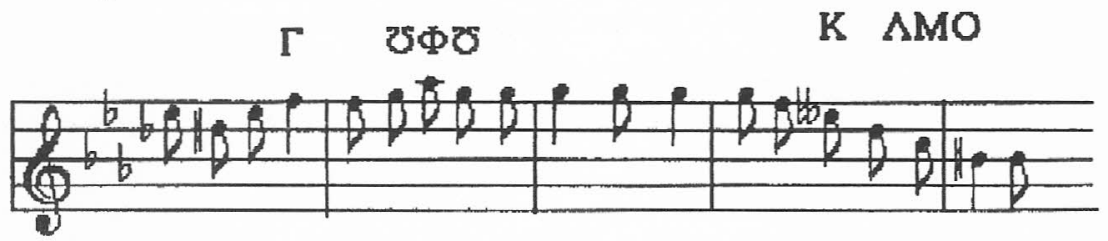

[lthi] kluta megalópolis Atthis, eukhaie[is]i phéroplóio...

Das dezessete sílabas desses fragmento (descontamos as primeiras duas, que faltam no documento original), a notação grega marca a altura exata de apenas oito, aquelas cuja entoação podia ser equivocada: a subida para o lá b do segundo compasso e a modulação (metabolé) do quarto. Se esse tipo de notação não visa reproduzir a melodia em sua integridade, muito menos se preocupa em estabelecer com ela algum tipo de isomorfismo. Em compensação, é exata quanto à definição das alturas, e por isso continuou a ser utilizada na Idade Média, com modificações superficiais, para fins teóricos e científicos.

A notação grega é funcional a uma concepção determinada do evento sonoro e, mais em geral, de todos os estímulos sensórios. Para Aristóteles, a sensação era uma alteração instantânea, ou seja, uma alteração que não passa por um processo de geração. $O$ instante da sensação, todavia, não é um ponto sem extensão: é um plenum, uma unidade indivisível. Aristoxenos, discípulo direto de Aristóteles, elaborou um sistema de definição das alturas e das durações baseado sobre os dados sensíveis, em aberta polêmica com os pitagóricos. Ele introduziu, inclusive, uma unidade indivisível de medida métrica, o chronos protos, que descende com toda evidência da concepção aristotélica do instante. $\mathrm{O}$ evento sonoro era portanto, na Grécia pós-aristotélica, uma corrente de sensações instantâneas, cada uma possuindo qualidades próprias que, não sendo geradas por um processo, independiam das qualidades do evento como um todo. Tarefa da notação, portanto, era estabelecer signos que definissem com exatidão essas qualidades, assim como as letras do alfabeto definem as qualidades dos fonemas, independentemente do significado que elas virão a assumir no contexto.

O conceito aristotélico de sensação instantânea entraria em crise, junto com o sistema musical antigo, no início da era cristã. Para um cristão, o instante não é um plenum, não tem existência própria: ele só se 
justifica enquanto parte de um movimento que tem seu alvo alhures, no verdadeiro Ser, imutável e eterno. O problema da sensação é transferido do plano imanente ao plano transcendente, de um instante pleno fora do tempo à tensão para um futuro que também se situa fora do tempo ${ }^{7}$. O que conta, então, já não é o evento sensível em si, mas o movimento espiritual que se manifesta ao longo de uma sequiência de eventos. E a notação tentará reproduzir justamente esse movimento.

Veja-se, por exemplo, a notação gregoriana correspondente às palavras Confiteantur Domino do gradual Misit Domino:

Figura 2

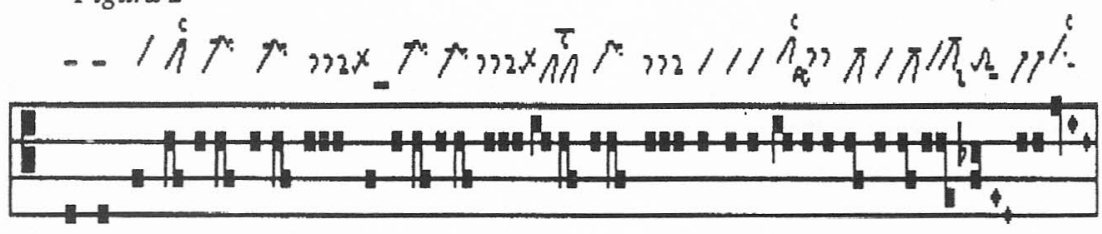

Confin- the-ar -

tur Domino

Esse fragmento deriva de um manuscrito confeccionado no mosteiro de Saint-Gall na segunda metade do século IX. Saint-Gall, na atual Suíça, foi um dos centros principais de elaboração da notação e da música gregoriana, e seus manuscritos são particularmente cuidados e detalha$\operatorname{dos}^{8}$. Na verdade, o fragmento citado acima é bastante indeterminado sobre alguns aspectos da melodia que hoje nos parecem essenciais, como a altura exata das notas, mas é, por outro lado, muito preciso quanto a nuanças que a notação moderna não reproduz senão vagamente. No início da melodia, por exemplo, sobre as quatro primeiras sílabas do tex-

7. Tentei descrever essa transição, sobretudo no que se refere ao pensamento agostiniano, em Santo Agostinho, a Música e o Tempo, tese de doutorado defendida na Faculdade de Filosofia da USP em 1998.

8. O Gradual Triplex de Solesmes transcreve a versão de Saint-Gall abaixo da notação gregoriana moderna, em tinta vermelha, pondo acima da pauta a notação de Laon, quando houver, em tinta preta. Não há notação de Laon para Misit Dominus. Sobre a importância da produção de Saint-Gall para a história da notação nemática, cf. Cardine, 1970, 26: A grafia atual da edição Vaticana, estilização da notação quadrada que surgiu quase em toda parte a partir dos séculos XIII e XIV, liga-se, em última instância, às notações antigas e, dentre outras, à notação sangaliana. 
to, a notação limita-se a sinalizar que as duas primeiras notas são graves (dois puncta, pontos ou traços horizontais) ${ }^{9}$, que a terceira é alcançada por um intervalo ascendente (virga, traço oblíquo ascendente de esquerda para direita) e que em seguida há um grupo composto por um movimento ascendente e um descendente (clivis, traço curvo que reproduz esse movimento) ${ }^{10}$. O copista não indica a altura da primeira nota da melodia nem a extensão dos intervalos seguintes, mas se preocupa em marcar uma letra $c$ (celeriter: rapidamente, ou em velocidade normal) acima do clivis, para sinalizar que o cantor deve executar imediatamente o salto descendente, sem apoiar sobre a nota aguda. $\mathrm{Na}$ tristroph $a^{11}$ seguinte, o último signo é completado por um pequeno traço horizontal embaixo, para significar um leve prolongamento da última nota. O prolongamento se justifica, aliás, pelo signo que segue, uma cruz oblíqua que muito provavelmente é uma teléia, um sinal de pontuação de origem bizantina, que marca a conclusão de uma frase ou membro de frase $^{12}$. Repare-se que, na distrofa sobre as sílabas (Do)mino, o traço horizontal é eliminado, sendo transferido para cima do clivis seguinte, indicando prolongamento da primeira nota deste (episema, ou traço superior). Dessa forma, a notação indica aqui, como nas três tristrophae anteriores, uma série de três notas com prolongamento da terceira. A única diferença é que, nesse caso, a série está no início de um segmento melódico e se articula imediatamente com a nota seguinte, enquanto anteriormente colocava-se no fim do segmento (primeiros dois casos) ou estava muito próxima dele (terceiro caso).

9. Segundo alguns pesquisadores, há uma diferença entre os pontos e os traços horizontais, os segundos indicando um prolongamento das notas. No que diz respeito a esse documento, tal interpretação não é aconselhável para os puncta isolados, que são escritos sem exceção como traços horizontais. Quanto aos neumas compostos, porém, ela parece ter fundamento, como veremos ao falar do último neuma deste trecho.

10. Treitler $(1982,248)$ salienta que a classificação dos neumas em formas fixas, cada uma com um nome específico, se encontra nos manuscritos apenas a partir do século $\mathrm{XI}$, época em que começa a se firmar uma escrita mais regular, inclusive com uso de pautas. Tal classificação corresponde portanto a uma fase em que os neumas começam a se cristalizar num sistema de cifras, perdendo parte de seu caráter icônico a favor de uma nova ordem simbólica.

11. Distropha, tristropha: grupos de duas ou três notas iguais, marcadas por apóstrofos.

12. A teléia pertence a um sistema de signos chamados ekphonésis, no qual voltaremos a falar. 
Voltando ao início da melodia: o punctum que segue a primeira teléia é muito mais espesso. É possível que essa característica não seja casual, e que indique um apoio mais marcado sobre essa nota, apoio que pode consistir tanto num aumento de intensidade quanto numa maior duração ou, mais provavelmente, em ambos. Essa interpretação poderia parecer forçada, se traços desse tipo não aparecessem nos manuscritos de SaintGall em contextos mais complexos, onde a diferenciação deles é claramente intencional. Por exemplo, nessa passagem do gradual Salvum fac (GT 355):

Figura 3

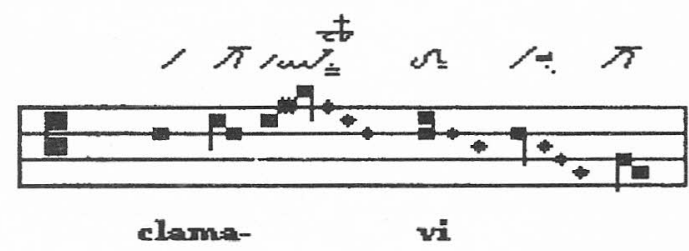

Aqui há dois grandes neumas: um de seis notas, no ápice do arco melódico, e um de quatro, próximo do fim ${ }^{13}$. No primeiro, a nota a ser acentuada e prolongada é a mais aguda, um fá, como a notação prescreve, com uma redundância que sugere um apoio muito marcado: um episema e duas letras significativas ( $t b=$ tenete bene, manter bastante). $\mathrm{O}$ segundo neuma é composto de uma virga e três puncta, sinalizando um intervalo ascendente seguido de um escala descendente de três notas. A virga não carrega episema, a primeira das notas descendentes é marcada por um traço espesso e realçado na borda direita, as outras duas por pontos simples. Nesse caso, não resta dúvida que a nota a ser acentuada e prolongada é a segunda.

Prosseguimos a análise do gradual Misit Domino: a notação gregoriana moderna, que se apoia em manuscritos medievais mais recentes e melodicamente inequívocos, marca um ré, nota mais aguda desse trecho, após a segunda tristropha. O manuscrito de Saint-Gall não assinala nada disso, limitando-se a colocar aqui dois clives, perfeitamente iguais aos outros. Em compensação, põe entre o dois neumas a letra significativa $t$ (tenete), que provavelmente indica algo diferente dos

13. A classificação dos neumas a partir do número das notas é, naturalmente, moderna: originariamente, os neumas eram movimentos contínuos, e não somatórias de alturas distintas. 
episemas, utilizados em situações parecidas: um acréscimo de duração mais consistente, ou um rallentando distribuído ao longo de todas as notas dos neumas. É possível que na notação posterior, mais esquemática, a perda inevitável dessa nuance tenha sido compensada por uma nova disposição das alturas, transformando um acento intensivo-quantitativo em acento melódico.

O segundo ré da composição aparece no neuma ré-dó, no início do melisma sobre a sílaba (Domi)no. Como no caso anterior, se tivéssemos de nos basear apenas no manuscrito de Saint-Gall, nada impediria de ler esse clivis como um dó-LÁ, em analogia com os clives anteriores. Nesse caso, porém, a distropha seguinte também seria rebaixada, e haveria uma mudança bastante atípica da corda de recitação. Em oposição aos dois clives anteriores, esse carrega a letra significativa $c$ (celeriter), e portanto deve ser cantado rapidamente, ou na mesma velocidade das notas próximas. O signo embaixo, entre o clivis e a distropha, é também uma letra significativa, st (statim, imediatamente), que prescreve que não haja solução de continuidade entre os dois neumas. $\mathrm{O}$ clivis em questão, portanto, deve ser interpretado como uma ornamentação passageira, sem acentuação nem prolongamento, enquanto os anteriores, marcados por um $t$ (tenete), deveriam ser salientados no canto.

A notação gregoriana moderna não possui instrumentos para expressar essa distinção com a ênfase devida. O resultado é uma linha melódica bastante frouxa, que apresenta dois ápices seguidos sobre a mesma nota. A notação antiga, ao contrário, parece mais apropriada para identificar o ponto de maior tensão do arco melódico (não necessariamente o ápice melódico, ou não apenas isso), que cai evidentemente no lugar marcado pela letra $t$, depois de dois impulsos ascendentes interrompidos pela teléia.

O último segmento do nosso exemplo marca um espaçamento das durações, quase um rallentando final: três clives e duas virgae carregam episemas. A virga do último neuma composto é cantada celeriter, mas os dois puncta que seguem são diferenciados na escrita: o primeiro é um ponto, o segundo é um traço horizontal, que nesse caso indica certamente um prolongamento ${ }^{14}$.

14. O sinal abaixo do terceiro clivis desse segmento é outra letra significativa, $i$ 
A estruturação da melodia como uma série de impulsos melódicos direcionados, que apontamos como o princípio básico da música gregoriana, é realizada com clareza muito maior na escrita original do que em qualquer tipo de transcrição moderna. Em compensação, elementos como altura, duração e intensidade são nessa fase nuances de um movimento melódico unitário, mais do que parâmetros distintos e relativamente autônomos, como na música moderna, e a diferenciação deles na escrita é portanto apenas embrionária.

É verdade que, no trecho considerado, a notação não reproduz o movimento do arco melódico como um todo, mas apenas cada um dos impulsos que o compõem, tomados singularmente. O movimento geral da melodia deve ser reconstruído mediante as letras significativas, que são elementos simbólicos, e não icônicos. Em parte, isso é devido ao caráter do trecho escolhido, que é um recitativo ornamentado. Nesse mesmo gradual, quando a melodia é mais livre, a notação tende a reproduzi-la, deslocando os neumas no espaço. Por exemplo, no fim da segunda frase da antífona:

Figura 4

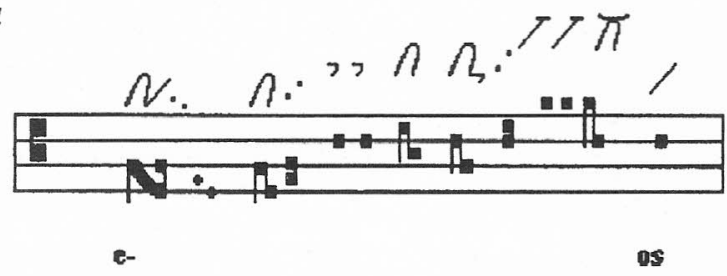

Esse tipo de recurso é comum nos manuscritos medievais, e a escrita que o utiliza é chamada diastemática (da palavra grega diastema, intervalo). Embora os tratados de paleografia costumem distingui-la da notação não diastemática, como se fossem duas famílias separadas, na verdade a diastematia apenas desenvolve um princípio que já estava embutido na forma dos neumas, e que Treitler propõe definir como princípio de direcionalidade (directionality) ${ }^{15}$. Em outras palavras, em ambos os tipos de escrita, a forma e a disposição do signo reproduz, e não apenas simboliza, o movimento sonoro. Na notação não diastemática, o

(inferius, mais baixo), a única de nosso exemplo a possuir significado melódico. Ela é posta justamente na articulação entre o recitativo e a cadência.

15. Treitler, 1982,250 e n. 
isomorfismo funciona apenas no interior de cada neuma, enquanto na diastemática ele se realiza também na disposição relativa dos neumas entre si; mas o princípio é fundamentalmente o mesmo.

Não é possível estabelecer uma prioridade cronológica, porque exemplos de ambos os tipos se encontram nos documentos mais antigos. Mas a escrita diastemática é posterior logicamente, por ser mais complexa e por ser aquela que deu origem à notação moderna. De qualquer forma, $o$ termo diastematia é impróprio para a fase que aqui nos interessa, porque a preocupação principal de toda escrita neumática, qualquer que seja sua disposição no espaço, é a direção da melodia, e não a representação dos intervalos.

\section{Gênese do Espaço Musical Gregoriano}

A progressão desenhada na páginas a seguir será mais lógica do que cronológica. Sistemas claramente simbólicos, próximos à notação grega, podem ter sido desenvolvidos contemporaneamente ou até após a escrita neumática. A notação em pautas recuperou muitos elementos simbólicos que a escrita neumática menosprezara, mas que continuaram a evoluir paralelamente, nos tratados teóricos ou na tradição oriental. Além disso, com exceção dos documentos gregos e de outras poucas fontes, todo o material remanescente que nos interessa remonta à mesma época, entre os séculos IX e XI, e nessa época todas as notações já apresentam grau muito avançado de sofisticação. A reconstrução da gênese delas, portanto, é altamente hipotética.

Uma outra observação: enquanto existiram e ainda existem sistemas de notação meramente simbólicos, como o grego antigo, um sistema de notação puramente icônico é provavelmente impossível. Os fatores a serem considerados no evento sonoro são demasiado numerosos e complexos para que seja possível reproduzi-los exaustivamente por meio de linhas sobre uma superfície. Até as notações neumáticas mais livres, portanto, procuram completar o quadro com elementos francamente simbólicos, como as letras significativas e os signos ecfonéticos, ou com figuras originariamente icônicas, mas que tendem a se cristalizar em símbolos, como o punctum, a virga, o episema. Todavia, o que distingue a notação gregoriana dentro da evolução da nossa escrita musical é, de um lado, a acentuação marcada dos elementos icônicos da escrita, ele- 
mentos que não existiam antes dela e que nunca mais desaparecerão totalmente; por outro lado, a interação contínua de elementos simbólicos e icônicos, sem uma distinção clara entre os parâmetros a serem representados de uma ou outra forma, o que sugere uma concepção do evento sonoro como um todo unitário e relativamente indiferenciado. De todas as escritas musicais, a gregoriana é a que mais se aproxima ao desenho. Ela é, como lembrava Cardine (1970, 13), um "gesto escrito".

A passagem da escrita musical antiga à neumática não é apenas uma mudança de formas e de métodos, mas também uma mudança de objeto: a notação grega procura simbolizar as qualidades sonoras de cada som, tomado individualmente; a notação neumática busca reproduzir o movimentos melódicos, dinâmicos e agôgicos entre os sons, enquanto o som singular, nela, tem uma importância muito reduzida. Em outras palavras: enquanto a notação musical grega indica as características objetivas do som, a notação neumática lida com uma forma musical entendida como movimento através e mediante os sons. Ao tentar traçar a linha evolutiva que leva de um sistema a outro, tentaremos dar conta dessa transição fundamental.

Por volta de 180 a. C., o gramático Aristófanes de Bizâncio elaborou um sistema de signos fonéticos, destinados a unificar a pronúncia da língua grega no universo expandido da koiné helenística. Tais signos eram chamados de prosódiai (lit.: para o canto, traduzido em latim por ad cantum = accentus), e estão na origem de muitos sinais ortográficos modernos. Eles incluíam os acentos agudo e grave (oxéia, baréia), chamados tonoi (tons), e os sinais de sílaba longa e breve (makrá, brakhéia), chamados khronói (tempos) - todos eles na grafia que conservaram até hoje. Havia ainda os pneúmata (respirações), que correspondem aos sinais de aspiração da grafia grega moderna (daséia: aspiração áspera; psylé: aspiração suave). A última categoria era a dos páthe, termo que poderíamos traduzir como afetos. Essencialmente, esse grupo era baseado num único signo, o atual apóstrofo (apostrophos), que, dependendo da posição, podia indicar efeitos expressivos particulares o ajudar no estabelecimento da distinctio ${ }^{16}$. Por exemplo, quando o apostrophos era colo-

16. As escritas grega e latina não possuíam sinais de pontuação. A divisão do texto em períodos, frases e incisos era tarefa do leitor e era uma arte específica, chamada distinctio e ensinada nas escolas de gramática. 
cado acima de uma linha de texto, conferia àquele trecho uma ênfase acentuada; quando se encontrava entre duas palavras, marcava uma separação; se estava abaixo da linha de texto, deitado, unificava duas palavras como uma ligadura, marcando continuidade na pronúncia.

O sistema das prosódiai tinha principalmente uma finalidade gramatical. Todavia, a distância entre gramática e música era tênue no mundo grego, na medida em que durações da sílabas e acento melódicos determinavam em larga parte seja a declamação, seja o canto $^{17}$. No mundo bizantino, a notação prosódica, enriquecida por signos suplementares, passou a ter uma significação mais propriamente musical, sendo utilizada na recitação dos salmos. Esse novo sistema de escrita é geralmente indicado como ecfonético ${ }^{18}$. Além da oxéia e da baréia, acentos agudo e grave, a ekphonésis inclui a sirmatiké, uma linha ondulada que indica uma recitação oscilante, como um tremolo; a kathiste, que prescreve um rebaixamento da voz como a baréia, mas sem acentuação; a kremaste, subida para o agudo com acentuação marcada; e assim por diante. $\mathrm{O}$ apóstrofo passa a indicar um tom médio-baixo sem acentuação particular, embora mantenha também, provavelmente, o significado de breve respiração antes da nota.

Contudo, a característica mais peculiar da notação ecfonética é que ela nunca se refere a uma única nota ou sílaba, mas sempre a trechos mais ou menos extensos de texto. Tais trechos eram delimitados, em seus começos e em seus fins, por dois signos iguais (duas oxéiai, duas baréiai etc.), que indicavam genericamente o tipo de recitação a ser adotado. Como exemplo, transcrevo um fragmento de uma leitura das Matinas de Páscoa ${ }^{19}$ :

17. A declamação antiga deveria soar muito musical para os ouvidos modernos, pelo menos em sua fase pós-clássica. Por volta de 30 a. C., Dioniso de Alicarnaxos recomendava que o orador não se afastasse do tom normal da fala mais de uma quinta no agudo ou no grave (de compositione verborum, cap. XI; cit. em Wellesz, 1949, 250). Um extensão maior daquela de grande parte de repertório gregoriano.

18. O termo é recente, tendo sido introduzido pelo teórico grego I. Tzetzes em 1885. Para os sistemas de notação bizantinos seguiremos sobretudo a descrição de Wellesz, 1949 , cap. X e XI.

19. Estando a notação ligada ao sentido do texto, e não à sua prosódia, utilizamos diretamente a tradução em português no lugar do original grego. O exemplo é reproduzido em Wellesz, 1949, 254, a partir de um manuscrito do século IX. 
Figura 5

Naguele tempo Jesús ressurgiu da morte, esteve entre as Apóstolos

,

edisse a eles + Apaz esteja convosco +

Os signos semelhantes a NN invertidos são kathistai, e indicam uma recitação plana e grave (o termo vem de kathistemi, que significa ser estável, ficar em repouso). A frase "esteve entre os Apóstolos" permanece no mesmo tom, mas os apóstrofos no começo e no fim indicam que deve ser delimitada por pequenas pausas. A frase seguinte, "e disse a eles", é marcada por um oxéia sobre a primeira palavra, e portanto deve ser declamada num tom mais agudo. A benção de Cristo está entre duas cruzes: são teléiai, que já encontramos na notação gregoriana, e que aqui também indicam pausas mais amplas.

Como resulta evidente por esse trecho, a notação ecfonética bizantina é essencialmente oratória, e sua finalidade principal é dramatizar o texto, tornando-o mais expressivo. No início deste século, o padre Jean-Baptiste Thibaut, na base de semelhanças formais, avançou a hipótese de que os neumas gregorianos derivariam dos signos ecfonéticos. A tese gozou de certo prestígio no começo deste século, mas em seguida foi quase totalmente abandonada. Com efeito, a escrita ocidental tomou emprestados muitos signos ecfonéticos, como o apóstrofo e a teléia, mas o princípios básicos das duas notações são muito diferentes ${ }^{20}$.

Pela mesma razão, a influência do taamin judaico sobre o gregoriano deve ter sido limitada. Com toda probabilidade, o sistema judaico, utilizado para a recitação dos salmos, evoluiu paralelamente à ekphonesis

20. A tese foi defendida por J.-B. Thibaut em Origine byzantine de la notation neumatique de l' Église latine, Paris, Picard, 1907. Ver a confutação dessa tese em Suñol, $1925,10-3$. Um dos documentos mais antigos da notação neumática ocidental parece à primeira vista confirmar a tese da origem oriental dos neumas, mas na verdade acaba reforçando a tese contrária: é um Gloria in excelsis escrito em duas colunas, a esquerda em grego (mas com letras latinas), a direita em latim. Sobre o texto grego, a melodia (também grega, como atestam vários manuscritos bizantinos) é notada em neumas paleo-francos, uma escrita muito simples, anterior à de Saint-Gall. No entanto, os neumas já apresentam uma disposição claramente diastemática, estranha à notação oriental, e figuras mais indeterminadas e cambiantes. Uma reprodução desse documento se encontra em Parrish, 1950, Pl. I. 
bizantina, a partir da raiz comum dos signos prosódicos alexandrinos. No taamin, no entanto, os signos não representam notas, intervalos ou tipos de emissão, mas fórmulas melódicas completas. Encontramos algo parecido na recitação salmódica gregoriana, nos signos (punctus) que indicavam as fórmulas para as flexae, os metra e as terminações de frase afirmativas e interrogativas; mas os símbolos judaicos são muito mais numerosos. De qualquer maneira, os punctus salmódicos são um caso à parte na escrita gregoriana e, mesmo que nesse caso haja uma influência do taamin, ela não seria extensível ao resto da notação.

Além da ekphonesis, limitada à notação do recitativo, os bizantinos dispunham de um método alternativo de escrita, utilizado para os outros gêneros de canto. Essa notação lembra de perto a escrita neumática ocidental na modalidade não diastemática, mas é muito mais precisa quanto à definição das alturas. Não há documentos dessa notação antes do século X, e portanto ela parece ser cronologicamente contemporânea ou posterior à notação gregoriana. Mas ela se mantém mais próxima da tradição grega, e por isso a consideramos aqui como um nível intermediário, de um ponto de vista meramente lógico.

Na notação bizantina do segundo tipo, que chamaremos neumática em oposição à ecfonética, cada signo indica não uma altura absoluta, mas um intervalo. Começa-se com um ison (lit.: o mesmo), um traço vertical levemente realçado na esquerda, semelhante ao punctum planum ocidental. $\mathrm{O}$ ison era utilizado também quando uma nota repetia a altura da anterior. Havia seis signos para a segunda ascendente, cada um indicando um tipo diferente de execução: em glissando, com élan, em staccato etc. O signo principal para esse intervalo, no entanto, era o oligon (lit.: pouco, ou pequeno [intervalo?]), cuja forma lembra a da virga gregoriana. O signos que indicavam a segunda descendente derivavam do apostrophos alexandrino (lit.: virado ao contrário). Os saltos de terça e de quinta, ascendentes e descendentes, também dispunham de signos específicos. O resto era indicado por signos compostos.

$\mathrm{Na}$ medida em que não visa representar alturas, mas relações entre alturas, a notação neumática bizantina representa um importante passo rumo à definição de uma forma do movimento sonoro em si, independente das características físicas dos sons que o compõem. No entanto, seus signos permanecem símbolos, cada um com um significado claramente delimitado e separado dos demais. Nenhum dele parece buscar uma 
analogia formal com o intervalo simbolizado, a não ser talvez o ison e o oligon, cujo isomorfismo, em todo caso, seria muito embrionário ${ }^{21}$ :

Figura 6

\section{Nota repetida (ison) \\ Segunda ascendente}

Segunda descendente

Terça ascendente

Terça descendente

Quinta ascendente

Quinta descendente

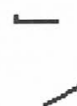

?

$\mathbf{3}$

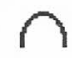

6

$x$

Em contraste com Kenneth Levy ("Byzantine rite, music of", NG III), para quem a notação bizantina é de caráter digital (simbólico), Egon Wellesz fala a esse respeito de "formas que imitam, mais ou menos, o movimento da melodia produzida pelas vozes humanas e, por conseqüência, os movimentos das mãos do regente" $(1949,287)$. No canto bizantino, como também no gregoriano, a prática de reger o coro com movimentos da mão era uma técnica complexa, chamada quironomia, que os textos afirmam ser bastante antiga ${ }^{22}$. Provavelmente, é impossível estabelecer se os neumas bizantinos derivam dos movimentos quironómicos ou vice-versa. Além disso, não há nenhuma evidência para decidir se esses movimentos imitavam os movimentos da voz, ou se limitavam a simbolizá-los. A comparação com a escrita parece favorecer a segunda hipótese.

A citação utilizada por Wellesz para descrever a prática da quironomia aponta, a nosso ver, na mesma direção:

21. Tabela extraída de Wellesz, 1949, p. 289.

22. Pela precisão, a quironomia teria sido introduzida na época dos hinógrafos Kosmas de Jerusalém e João Damasceno, entre os séculos VII e VIII. 
Após o Canonarca ler os versos do Troparion no livro, ele se põe na frente de todos como regente e, com movimentos variados da mão direita, com gestos ora verticais, ora horizontais, ora extensos, ora limitados, e com combinações de dedos, substitui os caracteres musicais ao indicar as diferentes figuras do canto e inflexões da voz; e assim os outros, olhando atentamente essa guia do canto, acompanham, por assim dizer, a estrutura inteira da melodia ${ }^{23}$.

Num contexto diferente, Helmut Hucke $(1980,448)$ cita um outro trecho da mesma testemunha, em parte análogo, em parte complementar a este:

Assim como os gregos raramente lêem ao declamar no púlpito, ainda mais raramente os músicos dirigem ou ensinam o canto pela notação escrita. Consideram essas faltas suficientemente compensadas, se um ministro, cuja voz possa ser ouvida facilmente pelos demais, ler no livro e sugerir aos dois coros os incipit dos versos a serem cantados; e, entre um e outro, utilizar sobretudo sinais para o conhecimento e a prática do canto, recorrendo a movimentos variados da mão direita e dos dedos, por contração, flexão, dilatação etc. (em Teófilo, Cedrenos chama isso de quironomia), como signos que expressem as diferentes notas e as fórmulas do canto ${ }^{24}$.

Essas descrições sugerem uma série de gestos codificados, capazes de indicar os intervalos melódicos um por um. Se confiarmos nesse testemunho, e não há motivo para não faze-lo, devemos acreditar que os músicos bizantinos não apenas reproduziam melodias já conhecidas a partir dos gestos do regente, mas também as aprendiam por esse meio. Isso, de fato, seria perfeitamente possível, se os gestos da quironomia correspondessem aos neumas: uma vez cantada a nota inicial, cada sig-

23. Post kómmata troparíon a Canonarchâ e libro suggesta, cantus moderatorem in omnium conspectu, variis manus dextrae motibus et gestibus, erectis nimirum, depressis, extensis, contractis, aut combinatis digitis diversas cantus figuras et vocum inflexiones characterum musicorum vice designare: atque ita hunc cantus ducem reliqui attente respicientes, velut totius modulationis regulam sequuntur. A citação é tirada do Euchologion sive rituale Graecorum, publicado em Paris em 1647 por Jacques Goar, um dominicano que visitou Constantinópolis entre 1631 e 1637.

24. Nam cum raro e libris in pulpito recitent Graeci, rariusque item musices notis exaratis cantum dirigant at instruant. Defectibus his consultum satis putaverunt, si minister quivis voce quae commode a reliquis audiretur, membratim per cola huic et alteri choro e libro suggereret, quicquid occurreret canendum: dum interim cantus notitia et usu magis insignes variis dextrae digitorumque motibus, contractione, inflexione, extensione etc. (quironomia vocavit Cedrenus in Teophilo) tanquam signis ad varias voces modulosque exprimendos uterentur. 
no indicava o intervalo seguinte, até a melodia se esgotar. A quironomia bizantina, que é sem dúvida mais precisa de qualquer tipo de regência ocidental, é ainda um sistema de símbolos. Em relação à notação grega, muda o objeto simbolizado: não mais sons simples, mas intervalos com caraterizações expressivas e/ou rítmicas, segmentos de movimento melódico. Esses segmentos, no entanto, perdem toda sua fluidez ao serem transportados no plano da representação, seja gestual, seja gráfica. Extraídos do contexto, cristalizam-se num vocabulário e tornam-se, eles próprios, objetos sonoros independentes.

A teoria musical, por outro lado, atribuía aos neumas significados particulares, e isso reforça o caráter simbólico deles. Sobre esse ponto, Wellesz se apoia em dois tratados teóricos bizantinos: a Arkhé de Micael Blemmides, e o anônimo Papadike. Nesse último tratado, o ison é assim definido:

O ison é princípio, meio, fim e totalidade [systema] de todos os signos da arte musical. Sem ele nenhum canto pode ter êxito. É chamado de áphonon não porque seja destituído de som, mas porque não é considerado uma nota: é cantado, mas nãoe é medido. Enquanto o canto permanece na mesma altura, o ison é cantado. Quando a voz sobe, canta-se o oligon; quando desce, o apostrophos ${ }^{25}$.

Micael Blemmedis desenvolve esses princípios:

O início vale por si mesmo, e sem ele não é possível estabelecer uma nota [phoné], nem ascendente nem descendente. É necessário que, se houver uma nota, haja ele também: de fato, ele tem um som [phoné], mas certamente não possui uma quantidade medida [ou seja: um valor fixo de intervalo ou de duração]. Eis um evento sonoro [akouson ti]: uma nota qualquer é a inicial [apodeiktiké; lit.: a que apresenta, traz ao conhecimento, inaugu$\mathrm{ra}$. Mas não é possível identificar a nota de outro jeito, se o ison não é posto desde o começo ${ }^{26}$.

Do ponto de vista da notação, o ison é a nota principal porque é a nota inicial, a partir da qual todos os intervalos seguintes são calculados. Todas as notas da melodia se referem a ele, enquanto ele não se refere a nenhuma nota anterior. Do ponto de vista melódico, não era exatamente isso o que acontecia: antes do primeiro ison, que correspondia à primeira

25. Cit. in Wellesz, 1949, 288, n. 2.

26. Idem, p. 290 , n. 2. 
sílaba do texto, havia uma fórmula convencional de introdução, cantada sobre sílabas sem significado (Aneanes, Neeanes, e outras combinações parecidas), marcadas à parte com uma notação estenográfica. Por exemplo ${ }^{27}$ :

Figura 7

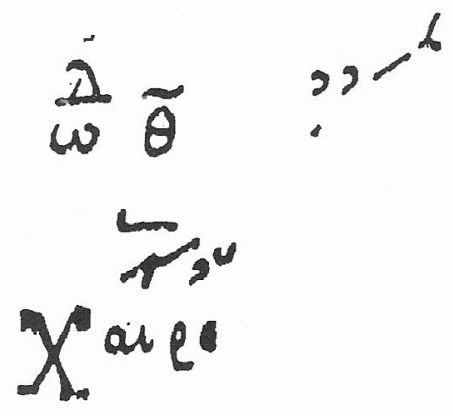

As letras tolelta e ómega são uma abreviação da palavra odé, hino; o theta com til é o número 9. Esse é portanto o nono hino do livro, um manuscrito da primeira metade do século XII. Geralmente, havia aqui uma outra letra, indicando o modo. Aqui é omitida, porque todos os hinos dessa seção do manuscrito são em primeiro modo, segundo o sistema grego de numeração (a cifra correspondente seria $\left.a^{\prime}\right)$. $\mathrm{O}$ grupo de neumas em alto a direita é a fórmula de entoação. $\mathrm{O}$ ponto indica a final do modo, que é Ré, como no primeiro modo gregoriano (a classificação modal bizantina é igual à ocidental). Os dois apóstrofos acima do ponto, porém, prescrevem que ela seja alcançada por uma linha descendente de uma certa extensão. Em sua transcrição, Wellesz ${ }^{28}$ sugere uma escala descendente por graus conjuntos, do Lá, tenor do modo, até a finalis. Os outros dois signos são uma oxéia e um hypsele. O hypsele marca um salto de quinta ascendente. A oxéia, quando sozinha, indica uma segunda ascendente acentuada; combinada com outro signo, perde o valor de intervalo, e mantém apenas o de acento dinâmico (torna-se muda, aphoné, segundo a terminologia bizantina). A fórmula introdutória, portanto, completa-se com um salto de quinta ascendente, uma volta ao Lá, com acento

27. Idem, p. 312.

28. Idem, p. 313. As páginas 311-316 contém uma descrição e uma transcrição argumentada da melodia inteira. 
sobre essa última nota. A primeira sílaba do texto carrega dois signos: o superior é um ison e indica a repetição do Lá; o inferior é uma hypostases, sinal marcado abaixo do signo intervalar, com valor expressivo. Esse, em particular, é um kratema, é prescreve uma ênfase marcada sobre a nota correspondente. Sobre a sílaba seguinte há um apostrophos (segunda descendente: Sol) e um outro signo (tzakisma) que indica um prolongamento rítmico correspondente a uma metade de tempo 29 .

Esse fragmento minúsculo pode proporcionar uma idéia da complexidade extrema e da precisão milimétrica desse tipo de notação. $O$ que nos interessa salientar aqui, no entanto, é sobretudo o estatuto da fórmula introdutória, que no gregoriano se reveste de uma função determinante na construção do arco melódico, enquanto na Igreja oriental é mantida à margem da composição. Ela permanece atrelada a sua função pragmática (é o incipit que o regente canta antes da quironomia), mas nunca chega a ser parte integrante da melodia. Virtualmente, está fora da música.

O canto propriamente dito começa com o estabelecimento do tenor, que é também a primeira aparição do ison, "início, meio, fim e totalidade dos sons". Dessa forma, a nota representada pelo ison se coloca conceitualmente numa posição mais próxima da antiga mesé, centro da melodia grega antiga, do que do tenor gregoriano, que é apenas um dos pólos da tensão melódica. No entanto, na passagem da tradição pagã à cristã, a referência central do sistema torna-se transcendente: o ison não pertence à ordem das notas, porque as notas, para um bizantinos, são essencialmente intervalos. Ele não tem duração medida, nem valor expressivo específico. Se combinado com um outro signo, este torna-se mudo (perde seu valor intervalar) e empresta ao ison seu significado rítmico e/ou expressivo.

A partir do ison, são geradas as notas, divididas em dois grupos: os Corpos (sómata) e os Espíritos (pnéumata). Os Corpos são os movimentos por graus conjuntos, baseados no oligon e no apostro-

29. Nessa peça, prolongamentos desse tipo se encontram em fim de palavras, em correspondência a acentos circunflexos no texto ou logo antes de prolongamentos maiores, que Wellesz indica com fermatas. Eles parecem corresponder às oscilações agógicas que encontramos no gregoriano, com a diferença que aqui tudo é minuciosamente medido. 
phos; os Espíritos são os saltos maiores. Um tratado musical anônimo explica:

Sem os Corpos os Espíritos não poderiam vir à existência. Sem os Espíritos, os Corpos não poderiam ser postos em movimento ${ }^{30}$.

Com o ison, o oligon é o único signo que não possui duração ou valor expressivo próprio. Portanto, esses dois signos não podem ser combinados, já que um não acrescentaria nada ao outro. Isso dá ao oligon um estatuto particular: ele é o único que não se submete ao ison, como um servo a um padrão: mesmo,

O oligon é como um outro $\mathrm{Si}$ em relação ao ison, e não é possível comandar a si explica Micael Blemmides ${ }^{31}$. Junto com esses dois signos, o apostrophos forma a tríade das notas soberanas (tonoi kyrioi), as únicas que podem ser combinadas com todas as outras. O apostrophos, no entanto, ocupa uma posição levemente inferior, porque pode se tornar mudo em determinadas combinações.

$\mathrm{Na}$ medida em que avançamos no exame do sistema de notação bizantino, uma cosmologia de tipo neoplatônico se desenha atrás dele, com traços sempre mais marcados: Ison, oligon e apostrophos (o Mesmo, o Pequeno Intervalo e a Inversão) parecem desempenhar o papel das três hipóstases plotinianas (a Unidade, a Díade Inteligência-Ser, a Alma). Esse caráter esotérico deriva provavelmente da tradição musical gnóstica, que no Oriente foi muito mais sólida e duradoura do que no Ocidente. Os gnósticos, seita filosófico-religiosa que fundia doutrina cristã, neoplatonismo e mistérios pagãos em complicadas cosmogonias, conferiam à música um poder mágico e alquímico, e estabeleciam correspondências entre as sete vogais, os sete planetas, e as sete notas de suas

30. Ms 811 da Biblioteca Patriarcal de Costantinópolis, cit. in Wellesz 1949, 289. Sobre este ponto, a terminologia bizantina é oposta àquela transmitida por Plutarco, segundo a qual o corpo da harmonia era constituído pelos intervalos harmônicos de quarta, quinta e oitava (cf. acima, 4.1.3., n. 27).

31. Cit. in Wellesz, 1949, 291. Infelizmente, Wellesz não fornece o texto original dessa importantíssima passagem. Eis a tradução inglesa: For the oligon is like another self in relation to the ison and one does not command oneself. 
escalas musicais, chamadas kentroi (centros). Utilizavam para finalidades mágicas ou rituais cantos sobre séries de vogais sem sentido, que provavelmente inspiraram as fórmulas de entoação bizantinas do tipo Aneanes, Neeanes etc.

Ao que parece, as especulações gnósticas foram incorporadas na gramática e na música bizantina. Um tratado musical conservado num manuscrito do século XIV, e conhecido como Hagiopolita (da cidade sagrada, ou seja, de Jerusalém), ironiza essas simbologias:

Seria delírio querermos copiar os gramáticos e macaquear seus trabalhos. Os gramáticos dizem que as vinte e quatro letras do alfabeto correspondem às vinte e quatro horas do dia e da noite; e alguns afirmam a mesma coisa para as vinte e quatro tonalidades! Os gramáticos dizem que as sete vogais representam os sete planetas, e alguns [músicos] dizem o mesmo para suas sete vogais [ou seja: as notas], e há outros exemplos ${ }^{32}$.

De fato, a música bizantina marca uma dissolução do corpo sonoro, assim como os gregos o entendiam, a favor de algo que poderiam definir como estética do intervalo. $O$ intervalo bizantino, no entanto, não é preenchido por um movimento subjetivo da alma, mas é visto como algo estático, uma espécie de corpo sonoro de segundo grau. Dessa forma, a cosmologia física que fundamentava a música grega não é substituída por uma psicologia, e sim por uma cosmologia metafísica.

Segundo a maioria dos pesquisadores, a notação neumática ocidental também derivaria das prosodiai elenísticas: virga, punctum e clivis seriam formas modificadas dos acentos agudo, grave e circunflexo, respectivamente. Os outros signos seriam combinações desses neumas fundamentais. O ponto fraco dessa hipótese é o punctum, que não se assemelha ao acento grave nem na forma, nem no nome. Para contornar essa dificuldade, imaginou-se que o acento grave teria se transformado num traço horizontal, posteriormente reduzido a um ponto. Mas não há evidências dessa evolução nos manuscritos. No artigo já citado (1983), Treitler propõe outra solução: os signos fundamentais derivariam dos signos utilizados para a distinctio, correspondentes aos signos de pontuação atuais. A virga seria, literalmente, uma vírgula; o punctum, um ponto. O fim de um inciso, marcado por uma vírgula, costumava ser

32. Cit. in Höeg, 1922, 333. 
declamado num tom elevado; o fim de uma frase, marcado por um ponto, num tom rebaixado. Por extensão, vírgula e ponto passariam a simbolizar uma nota aguda ou baixa. Todos os outros signos, inclusive o clivis, seriam gerados por combinações.

Gostaríamos de acreditar nessa tese, porque ela sugere que a notação cristã ocidental baseou-se desde o início no movimento geral da frase, para pormenorizá-lo em seguida em movimentos sempre mais detalhados. No entanto, é necessário admitir que a proposta de Treitler é tão hipotética quanto a outra. Sua vantagem é dispensar qualquer modificação na forma dos signos e em seus nomes. Em compensação, pressupõe uma evolução igualmente não demostrada em seus significados ${ }^{33}$.

Já falamos das características da escrita gregoriana em sua fase madura. Será útil agora abordar um outro método de notação, marginal porém significativo, que se encontra em tratados teóricos ocidentais do século IX. Essa notação é baseada sobre um único signo, a daséia, que na notação alexandrina indicava aspiração, e por isso é chamada notação daseiana. Originalmente, a daséia tinha a forma de um agá cortado ao meio:

A notação modifica de várias maneiras esse signo, e o utiliza em orientações diferentes, para dar conta de uma inteira gama de alturas ${ }^{34}$ :

Figura 8

\begin{tabular}{|c|c|c|c|c|}
\hline $79 \& 4$ & $5 P J N$ & $w^{2} \cdot d H d$ & $26+b$ & Tנד \\
\hline & & $\begin{array}{cccc}2 & \mathrm{~h} & \mathrm{c}^{\prime} & \mathrm{d}^{\prime} \\
l a & s & d 0^{\prime} & r^{\prime}\end{array}$ & & \\
\hline
\end{tabular}

33. A tese tradicional pode se apoiar em afirmações de teóricos antigos, ainda que muito esporádicas. Um tratado De arte musica do século X ou XI, por exemplo, afirma: de accentibus toni oritur nota quae dicitur neuma (da altura dos acentos surgem os signos chamados neumas; cit. in Suñol, 1925, 25, n. 3). Aureliano de Réomé (século IX) também observa que os neumas derivam dos acentos. Treitler $(1982,267)$ replica que, no texto de Aureliano, a palavra neuma indica as fórmulas melódicas, e não seus signos. O mesmo poderia ser dito para o primeiro texto, que não fala em figuras de acentos, mas em suas alturas.

34. Tabela extraída de APEL, 1957b, 220. 
$\mathrm{Na}$ prática, os signos derivados da daséia são apenas quatro, e correspondem aos quatro graus de um tetracordo dórico (primeiro modo eclesiástico). Virando esses quatro signos em todas as direções, o mesmo tetracordo é repetido em alturas diferentes. Para respeitar a seqüência dórica de tons e semitons, é necessário recorrer a notas alteradas sempre que o tetracordo não iniciar com um Ré ou com um Lá: Si b no tetracordo grave, Fá \# no mais agudo, e até um Dó \# no fragmento de tetracordo que fecha a escala. Tais características tornam a série bastante incômoda quando se trata de representar um arco melódico contínuo, mas muito útil para transpor linhas melódicas restritas em alturas diferentes. Essa de fato será sua utilização, como veremos.

Em si, essa notação é simbólica e não apresenta novidades relevantes em relação à notação grega, a não ser na escolha de um signo mais imaterial do que as costumeiras vogais e consoantes, e na maneira engenhosa com que é aproveitado. Guido de Arezzo atribui sua invenção ao abade Oddo de Cluny (século IX), mas ela se inspira evidentemente na notação bizantina, como aliás confirmam os títulos em grego dos tratados em que aparece pela primeira vez: Musica Enchiriadis e Scholia Enchiriadis (Manual de música; Manual em comentários).

$\mathrm{O}$ aspecto mais interessante, no entanto, é a disposição desses signos no papel. Em vez de serem escritos acima do texto, eles são dispostos em coluna à esquerda, enquanto as sílabas do texto são escritas na altura da nota correspondente. É assim que os autores da Musica e da Scholia Enchiriadis registram os primeiros exemplos conhecidos de organum paralelo. Por exemplo:

Figura 9

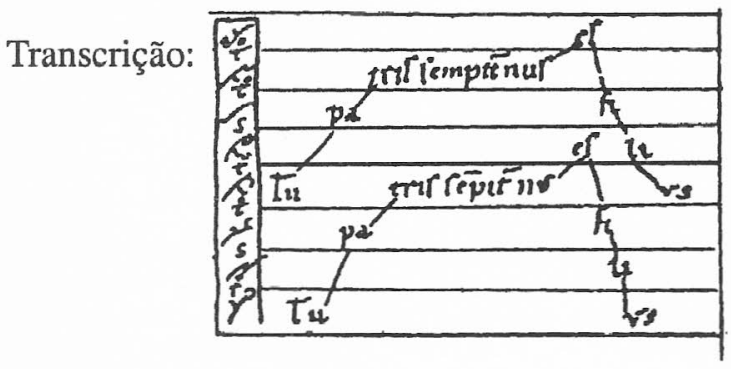


Figura 10

$\mathrm{F}: \div \circ+0$

Tu pa- tris sermpitermus ef fi- li- us

O exemplo mais impressionante de notação daseiana é a partitura anexa a uma cópia comentada do Musica Enchiriadis, conhecida como Tratado parisiense De organo. Transcrevo a primeira linha:

Figura 11

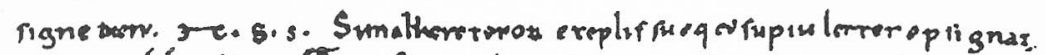

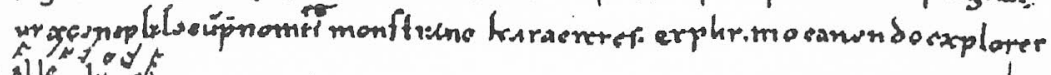
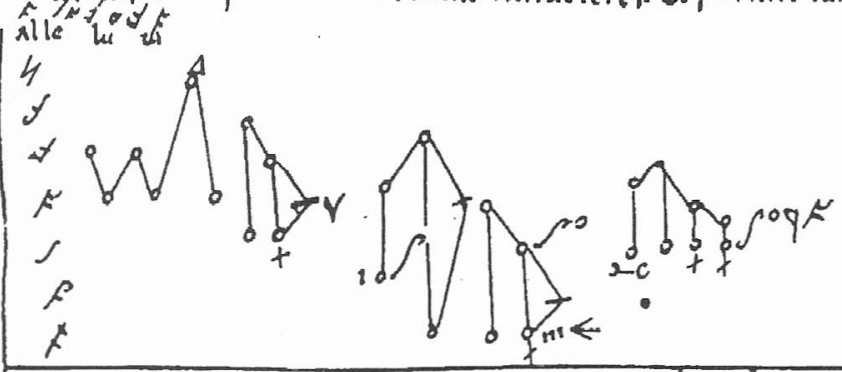

Transcrição:

Figura 12

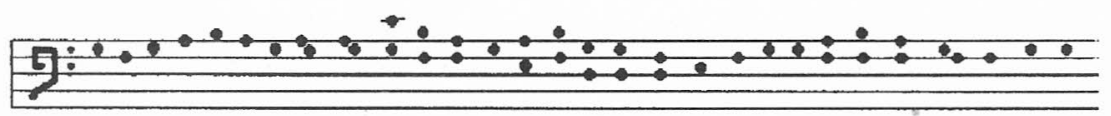

Alb- la- ia

Essa partitura, de aspecto tão moderno, é a mais antiga composição polifônica conhecida: uma elaboração a duas vozes da sequiência Benedicta sit. A disposição gráfica, com o incipit monofônico sobre a palavra Alleluia notado separadamente, lembra as partituras bizantinas. Com efeito, entre os séculos VIII e IX houve uma aproximação entre Oriente e Ocidente, devida em parte ao movimento iconoclasta (destruição das imagens: 726-787), que levou muitos monges orientais a fugir para o Ocidente trazendo seus manuscritos, em parte à política exterior 
dos Reis francos. Por duas vezes, em 752 e em 812, o Imperador de Oriente enviou um órgão como dom ao Rei dos Francos (Pepino e Carlos Magno, respectivamente). Os presentes despertaram enorme interesse, e é possível que a prática do organum paralelo tenha se desenvolvido a partir do estudo dos registros de ripieno de instrumentos desse tipo, ou da maneira de utilizá-los no acompanhamento ${ }^{35}$. É possível também que a prática dos tropos, interpolações musicais e/ou textuais nos cantos litúrgicos, que tiveram extraordinária difusão entre os séculos IX e XI, derivasse dos troparia, introduzidos oficialmente na liturgia bizantina logo após a revolta iconoclasta.

Tudo isso explica o campo de interesses do Musica Enchiriadis e do De organo de Paris, mas não lhe retira a originalidade. Esses tratados se aproveitam da precisão simbólica da notação oriental, mas a organizam numa disposição que torna intuitivamente visível o movimento sonoro. A relação entre texto e notação musical se inverte: já não é a linha do texto que carrega a música como um seu atributo, mas é o espaço da página, análogo e isomorfo ao espaço sonoro, que inclui texto e música como movimentos possíveis em sua superfície. Sendo esse espaço, justamente, uma superfície, não é difícil reconhecer que muitas linhas podem percorrê-la simultaneamente. Com efeito, o Musica Enchiriadis é o primeiro tratado a incluir uma teoria do contraponto, ainda que embrionária ${ }^{36}$.

Sob outro ponto de vista, a notação do Musica Enchiriadis é extraordinariamente pobre: nela, há apenas pontos no espaço, sem intensidade, duração ou outros caracteres específicos. Não há sons, mas apenas posições. Em outras palavras: ela é a primeira a reproduzir a estrutura de um evento sonoro mediante uma metáfora espacial exata e rigorosa, mas a estrutura representada é vazia, porque seus elementos não possuem qualidades. Num certo sentido, a solução do Musica Enchiriadis é

35. Ver os verbetes Organ (IV.2) e Organum (1), em New Grove XIII.

36. Para uma análise da seção do tratado dedicada à polifonia, v. Apel, 1957. Segundo o autor, whoever wrote the Musica Enchiriadis, erected for himself a monument of greater significance than that of a mere name. Not only did he leave for posterity the earliest information about polyphonic music, but he also treated this subject with much greater clarity and inner conviction than was done during the subsequent two undred years. Outros aspectos do tratado são abordados em Gallo, 1977, 3-4. Sobre os exemplos musicais da notação daseiana, v. tb. Apel 1942, 220-224. 
oposta e complementar à solução grego-bizantina. Esta descrevia pormenorizadamente o corpo sonoro (corpo físico, na Grécia clássica, corpo simbólico, em Bizâncio), abstraindo porém de sua posição dentro de um movimento sonoro contínuo; a notação daseiana, ao contrário, representa a posição em si, separada do corpo que a encarna. O que ela ressalta não é o ponto, mas a linha; não a nota, mas a quantidade do intervalo. Nisso, ela paga sua dívida à cultura bizantina.

Sem dúvida, a notação ocidental moderna está mais próxima ao Musica Enchiriadis do que ao Papadike. No entanto, sua origem não está na notação daseiana, mas na notação neumática gregoriana, em sua modalidade diastemática. Desta, a notação moderna herda a posição de compromisso entre os registros do símbolo e do ícone. De fato, ao encaixar-se nas pautas, os neumas perderam grande parte de suas capacidades descritivas: algumas de seus caracteres, como a virga e o punctum, passaram a ter significação rítmica. De qualquer forma, nossa notação manteve a ambição de representar não apenas (ou não tanto) os sons, mas sobretudo o movimento sonoro total que constitui a forma do evento musical. Por isso, ela se diferencia da maioria das outras notações musicais quanto a sua função e a seu estatuto: ela não é apenas um registro da obra, mas um instrumento de sua composição. Num certo sentido, a partitura é a própria obra:

[Kretzschmar] falou da mera aparência visual da música escrita e afirmou que, para o conhecedor, bastava um único olhar à folha pautada para obter-se uma impressão decisiva do espírito e do valor de uma composição. Ocorrera-lhe certa vez que no seu quarto se achasse aberto na estante $o$ trabalho de um diletante, que lho submetera, e um colega que, ao entrar, avistava-o bem de longe, gritou logo:

- Por amor de Deus, que porcaria tens aí?!

Por outro lado, descreveu-nos o prazer exímio que a mera imagem óptica de uma partitura de Mozart propicia aos olhos de peritos, a clareza da disposição, a bela distribuição dos grupos de instrumentos, a espirituosa e variada conduta da linha melódica. Qualquer surdo, exclamou ele, por inexperiente que seja em matéria de sons, deveria alegrar-se em face dessas suave visão ${ }^{37}$.

37. Th. Mann, Doutor Fausto, Rio de Janeiro, Nova Fronteira, 1984, 82-3, trad. Hebert Caro. 


\section{Bibliografia}

Apel, W. "The Earliest Polyphonic Composition and its Theoretical Background". Revue Belge de Musicologie, 1957, pp. 129-137.

- La notazione della musica polifonica. Firenze, Sansoni, 1984; tit. or.: Die Notation der polyphonen Musik. 900-1600 (1957).

Cardine, E. Primeiro Ano de Canto Gregoriano e Semiologia Gregoriana. São Paulo, Pallas Athena-Attar, 1989; tit. or.: Première Année de Chant Grégorien e Sémiologie Grégorienne, 1970.

Doutzaris, P. "La Rythmique dans la Poésie et la Musique des Grecs Anciens”. Revue de Etudes Grecs, XLVII (1934), pp. 297-345.

Gallo, F. A. Il Medioevo II, vol. 2 de "Storia della Musica" da Societá Italiana di Musicologia, Turim, EDT, 1981 (1977).

HöEG, C. "La Théorie de la Musique Byzantine". Revue de Études Grecques XXXV (1922), pp. 321-334.

HUCKE, H. "Towards a New Historical View of Gregorian Chant", em Journal of American Musicological Society XXXIII (1980), 3, pp. 437-467.

Parrish, C. G. The Notation of Medieval Music. New York, Pendragon Press, 1978 (1950).

Reese, G. La Musica nel Medioevo. Milão, Rusconi, 1990; tit. or.: Music in the Middle Ages, 1940.

SAcHs, C. La Musica nel Mondo Antico. Firenze, Sansoni, 1981; tit. or.: The Rise of Music in the Ancient World. East and West, 1943.

Suñol, G. M. Introduction à la Paléographie Musicale Grégorienne. Paris, Desclée, 1935; tit. or.: Introducció a la Paleografia Musical Gregoriana, 1925.

TREITLER, H. "The Early History of Music Writing in the West". Journal of American Musicological Society XXXV (1982), 2, pp. 237-279.

Wellesz, E. A History of Byzantine Music and Hymnography. Oxford, Clarendon Press, 1961 (1949). 